accretion have long been matters of much concern to civil engineers who, in the absence of precise investigations, were compelled to use empirical methods. Work in recent decades has been full of surprises. Though the widespread occurrence of steep-sided offshore canyons around the coasts is one of the surprises, this lies beyond the scope of the present work, where a beach is defined as an accumulation of loose material around the limit of wave action-extending through a zone divided into backshore, foreshore and offshore, from the extreme upper limit of wave action to the depth at which waves approaching from deep water first cause appreciable movement of the bottom materials. This scholarly, well-documented treatise first defines the four main factors on which the character of a beach depends, namely beach material, waves, tides, winds. It then considers briefly the three parallel methods of research-theoretical, experimental (especially wave-tanks such as that long in use in the Department of Geography at Cambridge) and field observations. A fourth approach, the historical, is mentioned, but sufficiently detailed information is rarely available. The main topics are then taken up in the order of waves, movement of material, beach profiles, effect of wind, classification of beaches and coasts, constructive and destructive wave action, and, finally, the marine cycle. Examples are drawn from world-wide sources with a particularly thorough examination of all the work around Britain.

Every point is substantiated by appropriate references, and nowhere is the reader left with the impression that all is adequately known and understood. Instead, the memory of the disastrous coastal floods of 1953 is still fresh in England; what may prove to be the tragic mistake of closing to scientific research the great natural laboratory of Dungeness is within the last few months. There is no doubt that protective works in one area have unexpected results in another; if half a million acres of tidal flat are awaiting 'reclamation', as some would claim, it is vital to know what will be the consequences elsewhere. The field of study covered in this book is part of the important new field of applied geomorphology. It is perhaps inevitable, if regrettable, that a new 'jargon' should arise that one needs to study the dilatancy and thixotropy of sediments. But perhaps the deliberate creation of new words is safer than the attempt to define by size granules, pebbles, cobbles and boulders, or to insist on new exact meanings for berm and runnel.

L. Dudley Stamp

\section{PRECIS OF PROGRESS IN BIOCHEMISTRY}

\section{Progress in Biochemistry}

A Report on Biochemical Problems and on Biochemical Research since 1949. By Prof. Felix Haurowitz. Pp. xii +357. (Basel: S. Karger; New York: Interscience Publishers, Inc.; London : Interscience Publishers, Ltd., 1959.) 60s. ; 8.50 dollars.

T 'HE fifth in Prof. Haurowitz's series of reports on progress in biochemistry deals with the advances in this field since 1949 , and we gather from the author's foreword that he was hesitant to prepare it. He comments that "limits of time and human endurance make it more and more difficult to grasp, let alone to master, the entire field of biochemistry". This cri de coeur will surely find an echo in many laboratories and lecture rooms, and for this reason alone, quite apart from the book's intrinsic merits, it is likely that Prof. Haurowitz's courage and virtuosity in grappling with the smothering excess of the printed word will earn the reader's gratitude.

But his claim to our thanks is more firmly founded for there can be no doubt that, within his terms of reference, he has written a most useful book, which gives fluent accounts of the progress made in all those aspects of the subject normally dealt with in the standard text-books. His method has its own particular merits : thus, except where a brief reminder may help the correlation of recent advances with established work, it is free from the necessity of giving the repetitious background to knowledge which necessarily swells each general text-book in turn. On the other hand, because it reports the work of a decade it is frequently able to focus topics which an annual review sees only as the indistinct blur of work-in-progress ; moreover, it is spared the uncritically comprehensive list of references which can so effectively throttle the text of more definitive reviews. In ten years a measure of sifting becomes possible, and the references retained and commented upon here seem to have been chosen with excellent discrimination.

Taken on this level, therefore, as a series of timely supplements to the general text-books, these volumes may be judged to have introduced successfully a new style of reporting into biochemistry. Necessarily they risk the defects of any anthology; there may be omissions and faults of emphasis. But it is certain that most readers will find new and stimulating expositions in the pages of this latest volume, and even be led to an appreciation of new aspects of the subject which had lain unregarded by them in the more specialist literature.

F. H. Malpress

\section{APPLIED MICROBIOLOGY}

\section{Advances in Applied Microbiology}

Vol. 1. Edited by Wayne W. Umbreit. Pp. xi 304. (New York: Academic Press, Inc.; London: Academic Press, Ine. (London), Ltd., 1959.) 9.50 dollars.

7 HIs volume is presented as the first of a projected new series of reviews on microbiological topics of interest to the practical microbiologist. Applied microbiology is, in its widest sense, a subject that covers or overlaps considerable areas of present-day scientific research. In recent years the synthetic and degradative powors of micro-organisms have been increasingly harnessed in the laboratory and factory, as microbial synthesis has often proved the only convenient method of preparing a number of compounds important in pharmacy or nutrition.

Three chapters are on general problems of largescale fermentation : P. Gerhardt and M. C. Bartlett classify the types of continuous fermentation and consider their theoretical basis and practical applications, M. Herold and J. Neçásek discuss the value of the use of antimicrobial agents to control contaminating micro-organisms that interfere with industrial formentation processes, and R. F. Robinson and R. S. Davidson give an interesting account of the problems 